\title{
Malpositioning of Central Venous Catheter from Right to Left Subclavian Vein: A Rare Complication
}

\author{
Takhar Rajendra P, Bunkar Motilal, Arya Savita ${ }^{1}$ \\ Departments of Respiratory Medicine and ${ }^{1}$ Dermatology, Govt. Medical College, Kota, Rajasthan, India
}

\section{Abstract}

Invasive monitoring with central venous catheter (CVC) is a valuable tool now a day in Intensive Care Units and in postoperative hemodynamically unstable patients. It is often employed for administering medications and parenteral nutrition. In most of the instances, these catheters are inserted using proper topographical landmarks and ultrasonography-guided methods. Central venous cannulation is associated now and then with unexpected complications despite the use of all precautions and help of imaging techniques. There is a wide variety of complications related to the central venous cannulation including malpositioning. Malpositioning of the catheter into contralateral subclavian is an extremely unusual event. Here, we report a rare case of malpositioning of CVC from the right to the left subclavian vein also we outline how the misplacement was identified and effectively managed.

Keywords: Central venous catheter, complication, malpositioning, subclavian vein

\section{INTRODUCTION}

Central venous catheter $(\mathrm{CVC})$ placement is a routine practice in management of critically ill patients of Intensive Care Units (ICU) and in the perioperative period for assessing or monitoring circulatory volume, cardiac status and central venous pressure (CVP), for intravenous fluid management, administration of cytotoxic drugs, hypertonic saline, blood and its products, and parenteral nutrition. ${ }^{[1]}$ Even with cautious placement using appropriate anatomical landmarks and insertion technique, central venous cannulation may be associated with many complications such as hematoma at insertion site, pneumothorax, inadvertent arterial puncture, nerve injury, thrombosis, infection, folding of catheter, cardiac tamponade, air embolism, arrhythmia, and sometimes catheter malposition. ${ }^{[2]}$ Under image guidance (ultrasonography [USG] or color Doppler or fluoroscope) accuracy of CVC insertion increases with minimal complications, but unavailability of resources and lack of experience with guided procedure is the reason behind routine practice of blind insertion of CVC leading to one or more complications. ${ }^{[3]}$ Such an uncommon complication of CVC insertion, malpositioning from right subclavian to left subclavian vein is discussed here.

\begin{tabular}{|l|l|}
\hline \multicolumn{2}{|c|}{ Access this article online } \\
\hline Quick Response Code: & \multicolumn{1}{|c|}{ Website: } \\
& www.ijccm.org \\
\cline { 2 - 2 } & \\
\hline
\end{tabular}

\section{Case Report}

A 23-year-old male admitted in the ICU with complains of sudden onset of pain abdomen followed by respiratory distress. Later on he was diagnosed as a case of intestinal perforation. On the day of admission his blood pressure was 110/60 mm of $\mathrm{Hg}$, pulse 86 beats/min, respiratory rate 22 breaths/min, $\mathrm{SpO}_{2} 99 \%$ on room air, and was afebrile on touch. Urgent laparotomy was carried out and remained asymptomatic for the next 2 days after surgery. On the $3^{\text {rd }}$ postoperative days, patient's blood pressure fall up to $84 \mathrm{mmHg}$ (systolic). Then $\mathrm{CVC}$ in the right subclavian vein was decided to assess the CVP, as well as for the administration of drugs and intravenous fluid. The right subclavian vein was cannulated with a $7.5 \mathrm{~F}$ triple lumen CVP catheter (Edward) using the standard Seldinger technique under USG guidance using all aseptic precautions. We used the lateral approach with the needle inserted longitudinally to the transducer. The guide wire was confirmed well in position in the vein. The guide

Address for correspondence: Dr. Rajendra Takhar P, Qtr No. 1/4, Medical College Campus, Kota, Rajasthan, India. E-mail: drrajtakhar@gmail.com

This is an open access article distributed under the terms of the Creative Commons Attribution-NonCommercial-ShareAlike 3.0 License, which allows others to remix, tweak, and build upon the work non-commercially, as long as the author is credited and the new creations are licensed under the identical terms.

For reprints contact: reprints@medknow.com

How to cite this article: Takhar PR, Motilal B, Savita A. Malpositioning of central venous catheter from right to left subclavian vein: A rare complication. Indian J Crit Care Med 2017;21:799-801. 
wire movement was free at insertion and during its removal after the placement of the CVP catheter. All channels of the CVC were aspirated for blood and fixed at $15 \mathrm{~cm}$. On attaching the transducer to the monitor the CVP waveform appeared dampened, and despite all described standards measures it could not be improved [Figure 1]. A chest radiograph performed after insertion to confirm the position of catheter revealed that it has migrated in the left subclavian vein [Figure 2]. The right subclavian CVC was removed and reintroduced under color Doppler guidance with modified Seldinger technique. The guide wire was confirmed well in position in the vein - it could be traced much beyond the subclavian vein. A repeat chest radiograph confirmed the correct placement with normal CVP is tracing [Figure 3].

\section{Discussion}

Correct placement of the $\mathrm{CVC}$ is an essential prerequisite for accurate monitoring of CVP (pressure waveforms/measurements) and long-term use of the catheter. The malpositioned catheter can be suspected when there is erroneous CVP value and suboptimal waveform pattern. ${ }^{[4]}$ Normally, the tip of CVC is placed, where the superior vena cava and right atrium merge. On chest radiograph, it seems to be $2 \mathrm{~cm}$ proximal to the pericardial line. ${ }^{[5]}$ Sometime the tip of catheter does not terminate to desired level, leading to malposition, which may occur at the time of insertion or later as a result of spontaneous migration due to anatomic positioning or pressure changes within the thoracic cavity induced by coughing, sneezing, and straining or weight lifting. A high infusion flow rate can also make the tip migrate. The approach and the type of vein cannulated, can affect the probability of catheter malposition, smaller caliber vein having more chances of malpositioning. ${ }^{[6]}$ The overall incidence of malposition is more for subclavian vein than internal jugular vein (IJV). However, among IJVs, left IJV malposition is more than the right. In a systemic review, Ruesch et al. ${ }^{[7]}$ reported that catheter malposition rates were $5.3 \%$ and $9.3 \%$ for IJV and subclavian vein respectively. Identification of CVC malpositioning is not easy to identify as the even free flow of blood from catheter lumen after placement does not rule out the malposition. ${ }^{[8]}$ An absent CVP waveform on the multi-parameter monitor despite checking for tube blockage, zeroing of the system and excluding transducer and cable malfunction, is an important clue to identify misplacement of CVC tip as in our case.

Detailed knowledge of venous anatomy is a prime requirement for correct positioning of CVC. Chest X-ray should be done postprocedure to rule out malposition, but should be avoided as a first investigation for repositioning of misplaced catheter. Image guided (USG, color Doppler or fluoroscopy) CVC insertion is a simple technique but needs practice and experience, results lower technical failure, faster access, and reduction in mechanical complication. ${ }^{[9]}$ The intraluminal electrocardiogram guidance and the flush test can also guide the correct placement of CVC tip. ${ }^{[6]}$ Color Doppler is considered better than the B-mode, gray-scale USG guidance in percutaneous insertion of CVC as it:

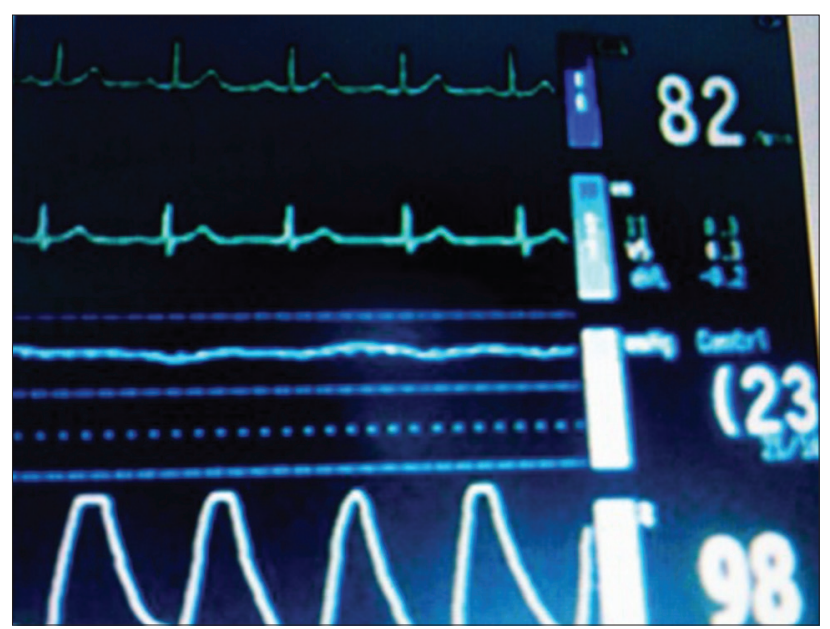

Figure 1: Multi-parameter patient monitor showing dampened/absent central venous pressure waveform with abnormal value

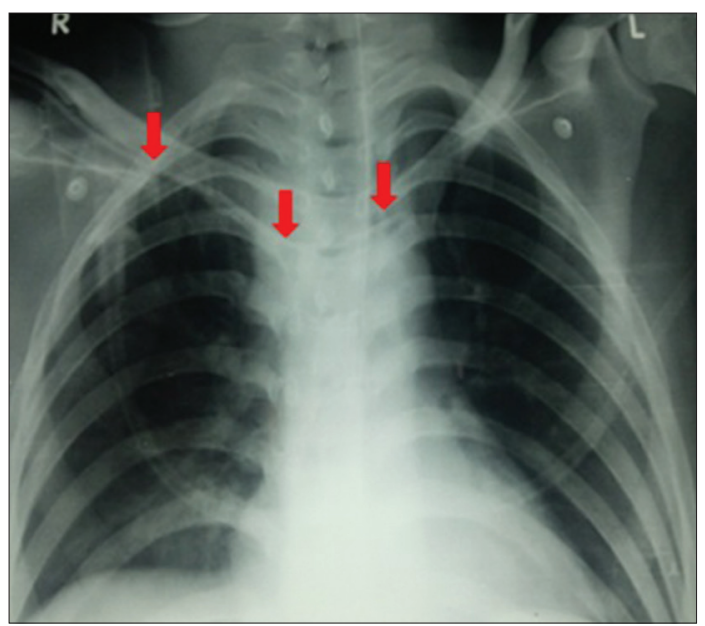

Figure 2: Chest X-ray posterioranterior view showing malpositioning of the central venous catheter from right to left subclavian vein

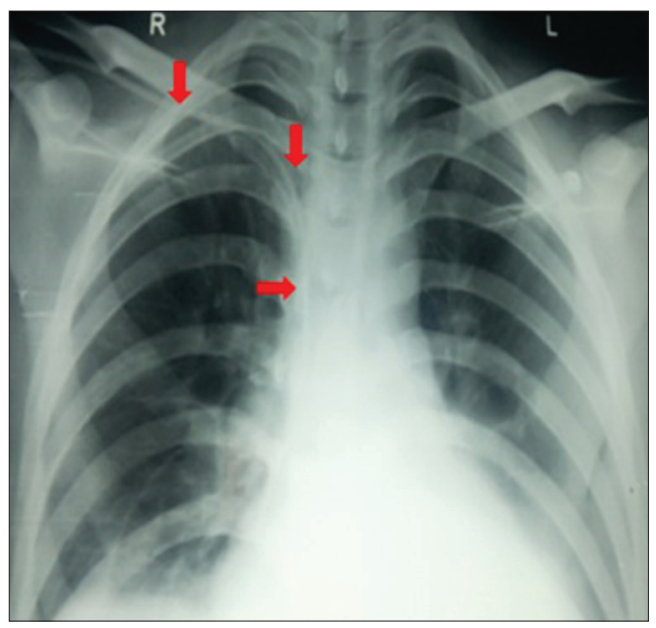

Figure 3: Repeat chest X-ray showing correct position of central venous catheter after correction under guidance of color Doppler

(a) Distinguishes between arterial flow from venous (b) is better in visualization of the shaft and tip of the needle, 
especially, when the needle is moving, or when the beam needle angle is narrow; (c) has improved targeting of vessels (d) avoidance of interposed other vascular structures during CVC insertion as in our case; (e) better visualization of poorly echogenic catheters, allowing proper placement; and (f) promptly detect complications if any, including active bleeding, after withdrawal of the needle. ${ }^{[10]}$

\section{Conclusion}

The interpretation of CVP waveforms and pressure measurements on a multi-parameter monitor may be helpful in identifying the cases of catheter malposition. The chest radiographs can be used to establish the diagnosis. Whenever feasible, use of color Doppler or other form of imaging (USG or fluoroscopy) to guide the $\mathrm{CVC}$ insertion procedure may prevent the malpositioning of the catheter as well as other procedure related complications.

\section{Acknowledgment}

We acknowledge all the staff involved in the care of the patient.

\section{Financial support and sponsorship}

Nil.

\section{Conflicts of interest}

There are no conflicts of interest.

\section{RefEREnCES}

1. Ghatak T, Azim A, Baronia AK, Muzaffar SN. Malposition of central venous catheter in a small tributary of left brachiocephalic vein. J Emerg Trauma Shock 2011;4:523-5.

2. de Jonge RC, Polderman KH, Gemke RJ. Central venous catheter use in the pediatric patient: Mechanical and infectious complications. Pediatr Crit Care Med 2005;6:329-39.

3. Karnawat R, Mohammed S, Biyani G. A Rare malposition of central venous catheter inserted through internal jugular vein. Int J Life Sci Res 2014;2:27-9.

4. Agrawal P, Gupta B, D'souza N. Coiled central venous catheter in superior vena cava. Indian J Anaesth 2010;54:351-2.

5. Coskun D, Mahli A, Oncul S, Ilvan G, Dalgic A. Malposition of subclavian vein catheter inserted through indirect technique in a pediatric liver transplantation: A case report. Cases J 2009;2:7998.

6. Prabaharan B, Thomas S. Spontaneous migration of central venous catheter tip following extubation. Saudi J Anaesth 2014;8:131-3.

7. Ruesch S, Walder B, Tramèr MR. Complications of central venous catheters: Internal jugular versus subclavian access - A systematic review. Crit Care Med 2002;30:454-60.

8. Hohlrieder M, Schubert HM, Biebl M, Kolbitsch C, Moser PL, Lorenz IH. Successful aspiration of blood does not exclude malposition of a large-bore central venous catheter. Can J Anaesth 2004;51:89-90.

9. Fragou M, Gravvanis A, Dimitriou V, Papalois A, Kouraklis G, Karabinis A, et al. Real-time ultrasound-guided subclavian vein cannulation versus the landmark method in critical care patients: A prospective randomized study. Crit Care Med 2011;39:1607-12.

10. Longo JM, Bilbao JI, Barettino MD, Larrea JA, Pueyo J, Idoate F, et al. Percutaneous vascular and nonvascular puncture under US guidance: Role of color Doppler imaging. Radiographics 1994;14:959-72. 